\title{
An operative case of hepatic pseudolymphoma difficult to differentiate from primary hepatic marginal zone B-cell lymphoma of mucosa- associated lymphoid tissue
}

\author{
Michihiro Hayashi ${ }^{1 *}$, Noboru Yonetani ${ }^{2}$, Fumitoshi Hirokawa ${ }^{1}$, Mitsuhiro Asakuma', Katsuhiko Miyaji ${ }^{3}$, \\ Atsushi Takeshita ${ }^{4}$, Kazuhiro Yamamoto ${ }^{5}$, Hironori Haga ${ }^{6}$, Takayuki Takubo ${ }^{2}$, Nobuhiko Tanigawa ${ }^{1}$
}

\begin{abstract}
Hepatic pseudolymphoma (HPL) and primary hepatic marginal zone B cell lymphoma of mucosa-associated lymphoid tissue (MALT lymphoma) are rare diseases and the differential diagnosis between these two entities is sometimes difficult. We herein report a 56-year-old Japanese woman who was pointed out to have a space occupying lesion in the left lateral segment of the liver. Hepatitis viral-associated antigen/antibody was negative and liver function tests including lactic dehydrogenase, peripheral blood count, tumor markers and soluble interleukin-2 receptor were all within normal limit. Imaging study using computed tomography and magnetic resonance imaging were not typical for hepatocellular carcinoma, cholangiocarcinoma, or other metastatic cancer. Fluorodeoxyglucose-positron emission tomography examination integrated with computed tomography scanning showed high standardized uptake value in the solitary lesion in the liver. Under a diagnosis of primary liver neoplasm, laparoscopic-assisted lateral segmentectomy was performed. Liver tumor of maximal $1.0 \mathrm{~cm}$ in diameter was consisted of aggregation of lymphocytes of predominantly B-cell, containing multiple lymphocyte follicles positive for CD10 and bcl-2, consistent with a diagnosis of HPL rather than MALT lymphoma, although a definitive differentiation was pending. The background liver showed non-alcoholic fatty liver disease/early non-alcoholic steatohepatitis. The patient is currently doing well with no sign of relapse 13 months after the surgery. Since the accurate diagnosis is difficult, laparoscopic approach would provide a reasonable procedure of diagnostic and therapeutic advantage with minimal invasiveness for patients. Considering that the real nature of this entity remains unclear, vigilant follow-up of patient is essential.
\end{abstract}

\section{Background}

A primary hepatic lymphoma (PHL) is defined as lymphoma localized and limited in the liver [1], not the secondary involvement of high- or intermediate grade non-Hodgkin's lymphoma, and accounts for less than $1 \%$ of all extranodal lymphomas [2]. Among them, a primary hepatic low-grade marginal zone B cell lymphoma of mucosa-associated lymphoid tissue (MALT lymphoma) is extremely rare.

\footnotetext{
* Correspondence: sur083@poh.osaka-med.ac.jp 'Department of General and Gastroenterological Surgery, Osaka Medical College Hospital, 2-7 Daigaku-machi, Takatsuki, Osaka 569-8686, Japan Full list of author information is available at the end of the article
}

On the other hand, hepatic pseudolymphoma (HPL), also termed as reactive lymphoid hyperplasia, or nodular lymphoid lesion, is extremely rare disease and characterized by the proliferation of non-neoplastic, polyclonal lymphocytes forming follicles with an active germinal center [3], and most importantly, is mimicking clinicopathologically to low grade lymphoma including MALT lymphoma.

The etiology, pathogenesis and clinical implications of these two diseases remain unknown to a large extent. Reported underlying liver diseases include chronic viral hepatitis, autoimmune liver diseases, etc [4].

(c) 2011 Hayashi et al; licensee BioMed Central Ltd. This is an Open Access article distributed under the terms of the Creative Commons 
Since clinical diagnosis is often difficult especially at its earlier stage, surgical resection appears a mainstay for diagnostic/therapeutic purpose.

We herein present a laparoscopically operated case of hepatic pseudolymphoma which was difficult to differentially diagnose from primary hepatic MALT lymphoma, and discuss the clinicopathological features and clinical implications of these two disease entity.

\section{Case presentation}

In April 2009, a 56-year-old Japanese woman was pointed out to have a space occupying lesion in the lateral segment of the liver on abdominal ultrasonography during health examination. Her social and family history was noncontributory and she had a previous medical history of appendectomy for acute appendicitis and laparoscopic cholecystectomy for cholecystolithiasis. She showed no abnormal physical findings, including lymphadenopathy and hepatosplenomegaly.

Laboratory findings of blood examination were almost normal, including blood cell counts and differentiation, serochemical tests including liver enzymes and lactate dehydrogenase (LDH), hepatitis viral associated markers including hepatitis B virus surface antigen (HBsAg), hepatitis $B$ virus core antibody ( $\mathrm{HBcAb})$ and hepatitis $\mathrm{C}$ virus (HCV) antibody. Also, tumor markers including carcinoembryonic antigen and carbohydrate antigen 19-9, alpha-fetoprotein (AFP), fucosylated AFP (L3-AFP), protein induced by vitamin-K absence or antagonist II (desgamma carboxy prothrombin, PIVKA-II), and soluble interleukin 2 (s-IL2) receptor were within normal limits.

Abdominal ultrasonography showed 15-mm-diameter hypoechoic in segment 3 in the liver, and on enhancement study, it showed slight enhancement of ring-like in the peripheral but not in the entire tumor, the center of which being minimally enhanced, which indicated metastatic tumor rather than hepatocellular carcinoma (HCC).

On abdominal computed tomography (CT) scan (Figure 1), 15-mm-diameter low density area was demonstrated before contrast material injection, which was enhanced in early arterial phase and subsequently washed out in the late phase after contrast material injection, not incompatible with HCC. Other organs including regional or para-aortic lymph nodes showed no abnormal finding.

On magnetic resonance imaging (MRI, Figure 2), the hepatic tumor was low signal intensity in T1-weighted imaging and slight high signal intensity in T2-weighted imaging, and low intensity in hepatobiliary phase 20 minutes after injection of gadolinium ethoxybenzyl diethylenetriamine pentaacetic acid (Gd-EOB-DTPA, Primovist, Bayer Schering Pharma), and on dynamic Gd-EOB-DTPA MRI protocol not clearly visualized during arterial dominant phase and slight ring-like

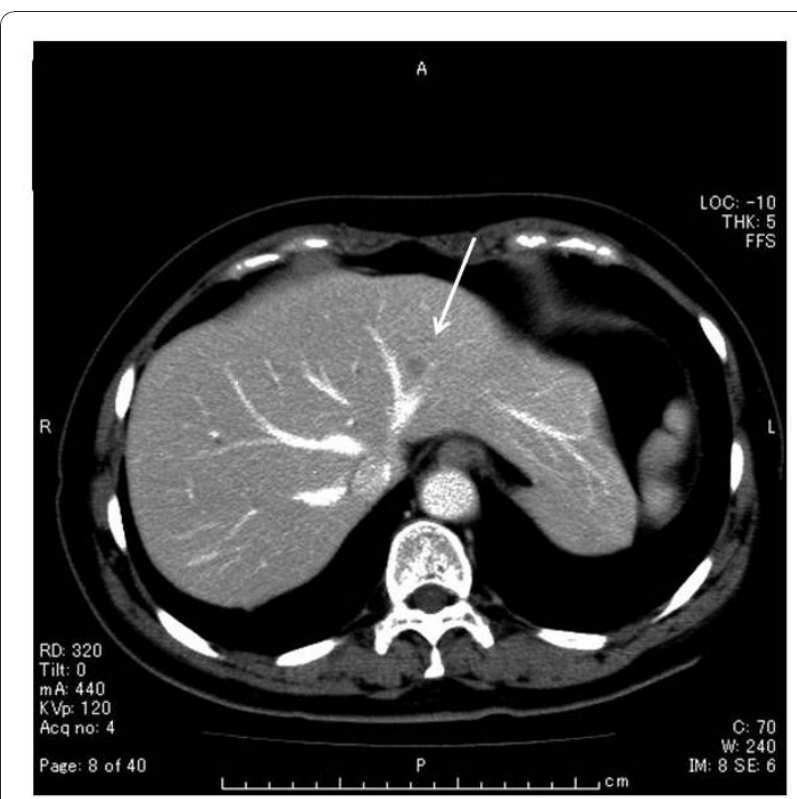

Figure 1 Unenhanced CT scan showed low density area of 1 $\mathbf{c m}$ in diameter in the segment 3 of the liver (arrow). Contrastenhanced CT scan during arterial phase showed minimally peripheral ring enhancement. No lymphadenopathy or hepatosplenomegaly was observed.

enhancement persisted, indicating hypovascular tumor, such as cholangiocarcinoma or liver metastasis.

On gastric fiberscope examination, atrophic gastritis was noted without evidence of MALT lymphoma. She had previously received eradication treatment for Helicobacter pylori. Colonoscopy examination found no other lesions.

In a fluorodeoxyglucose-positron emission tomography examination integrated with computed tomography scanning (FDG-PET CT, Figure 3), the tumor was revealed to have a high standardized uptake value (SUVmax: 3.6) for FDG. No other site showed FDG uptake, suggesting that liver tumor is not secondary from malignant lesions of other organs.

Abdominal angiography revealed small tumor stain in the tributaries of A2 during arterial phase; hence transcatheter arterial infusion of epirubicin and lipiodol was performed under the diagnosis of small HCC.

Percutaneous needle biopsy was performed, but failed to provide with definitive diagnosis regarding the tumor partly due to inappropriate material obtained because of the size of the targeted tumor, except for chronic hepatitis of minimal grade activity and fibrosis (A1/F1, according to the New Inuyama Classification [5], and hepatocyte ballooning with fatty degeneration being noted.

In November 2009, under a clinical diagnosis of primary malignant liver tumor, laparoscopic-assisted lateral segmentectomy was performed. 

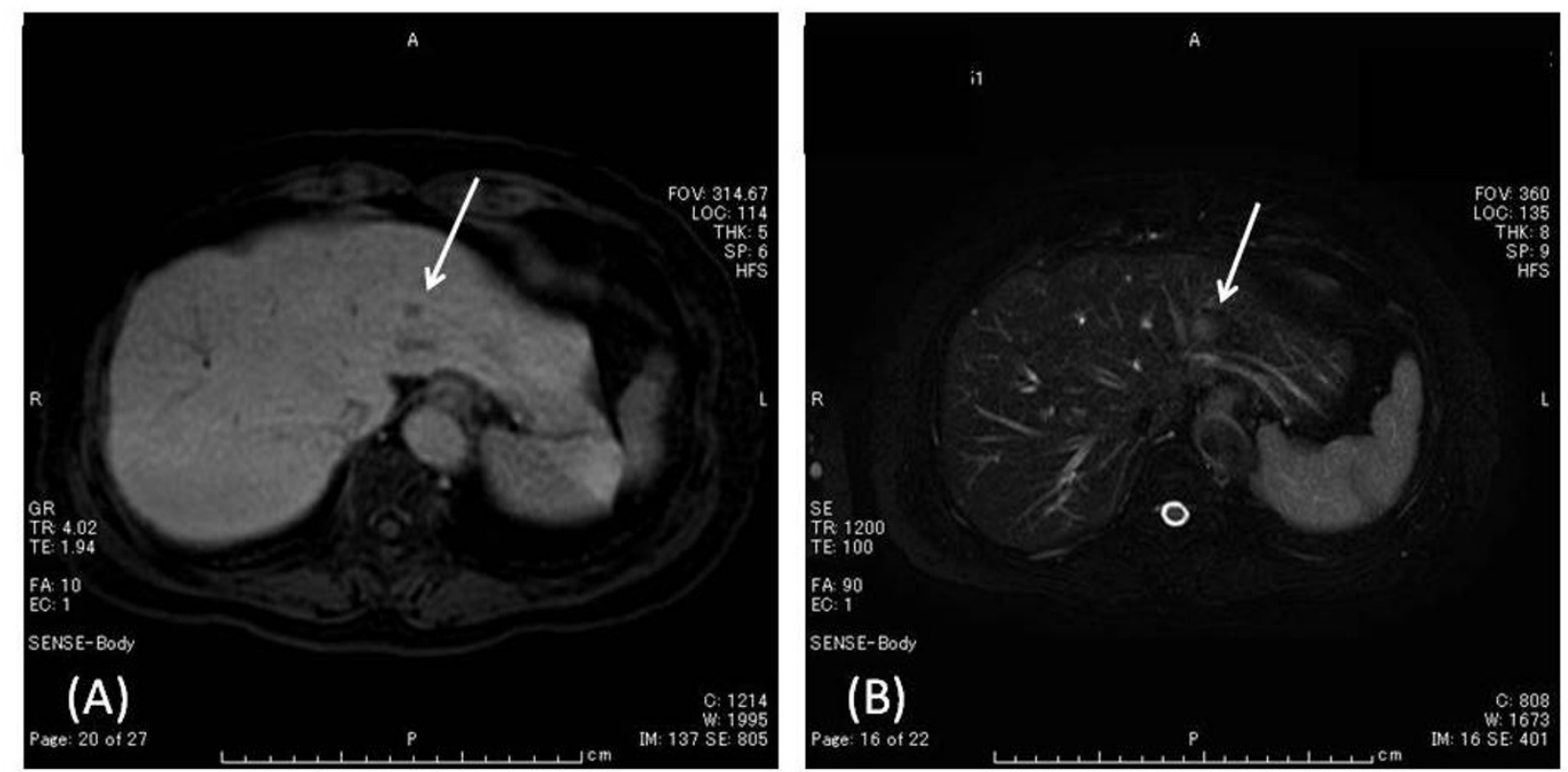

Figure 2 Magnetic resonance imaging (MRI), the hepatic tumor (arrow) was low signal intensity in T1-weighted image (A) and slight high signal intensity in T2-weighted image (B), and low signal intensity in hepatobiliary phase after Gd-EOB-DTPA injection, and on dynamic Gd-EOB-DTPA MRI protocol not clearly visualized during arterial dominant phase with slight ring-like enhancement persisting, indicating hypovascular tumor, such as cholangiocarcinoma or liver metastasis.

On macroscopic examination, there was a grey-white solid tumor, measuring $1.0 \mathrm{~cm}$ in largest diameter (Figure 4). The tumor was completely excised. On microscopic examination, the tumor in the liver was composed of dense lymphocytic infiltration including multiple lymphoid follicles with germinal centers (Figure 5A). The interfollicular areas were expanded and filled with small to medium-sized lymphocytes with pale

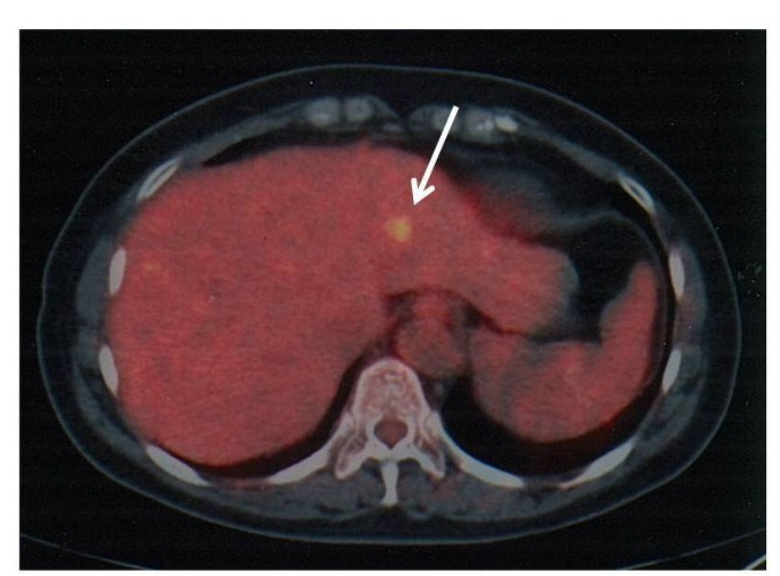

Figure 3 FDG-PET CT demonstrated the tumor had a high standardized uptake value (SUVmax: 3.6) for FDG. No other site showed FDG uptake, suggesting that liver tumor is not secondary from malignant lesions of other organs. cytoplasm and cellular atypia (Figure 5B, C), most of which were positive for CD20 and bcl-2 (Figure 5D, E), and negative for CD5 and CD10. Lymphoepithelial lesions with bile duct epithelium destruction by lymphoid tumor cells were noticed (Figure 5F). At the edge of the nodule, lymphocytic infiltration extended into perinodular portal tracts (Figure 5G). Bile ducts were observed at the periphery of the nodule (Figure $5 \mathrm{H}$ ). Ki67 index of those lymphoid cells was $25 \%$. Taken together, these findings were consistent with diagnosis of both extranodal marginal zone B-cell lymphoma and

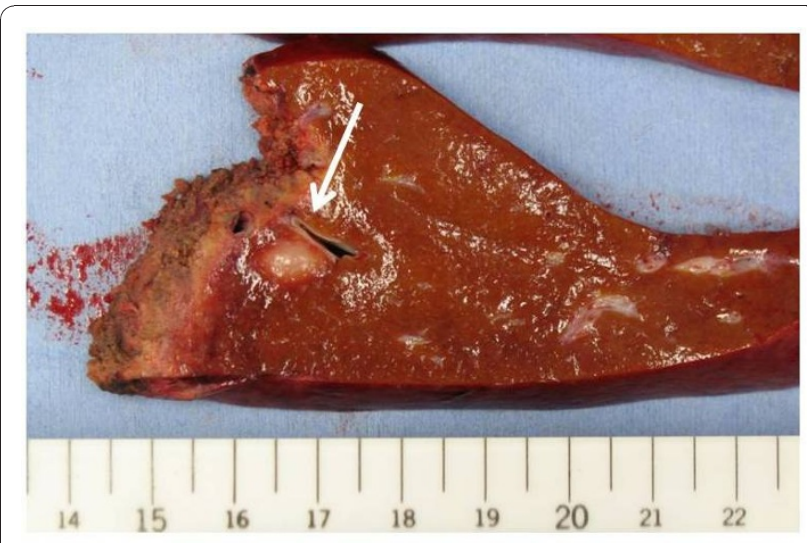

Figure 4 Resected specimen: section of the liver and $12 \times 10$ $\mathrm{mm}$, well-defined, light-tan, firm, solid nodule (arrow). 


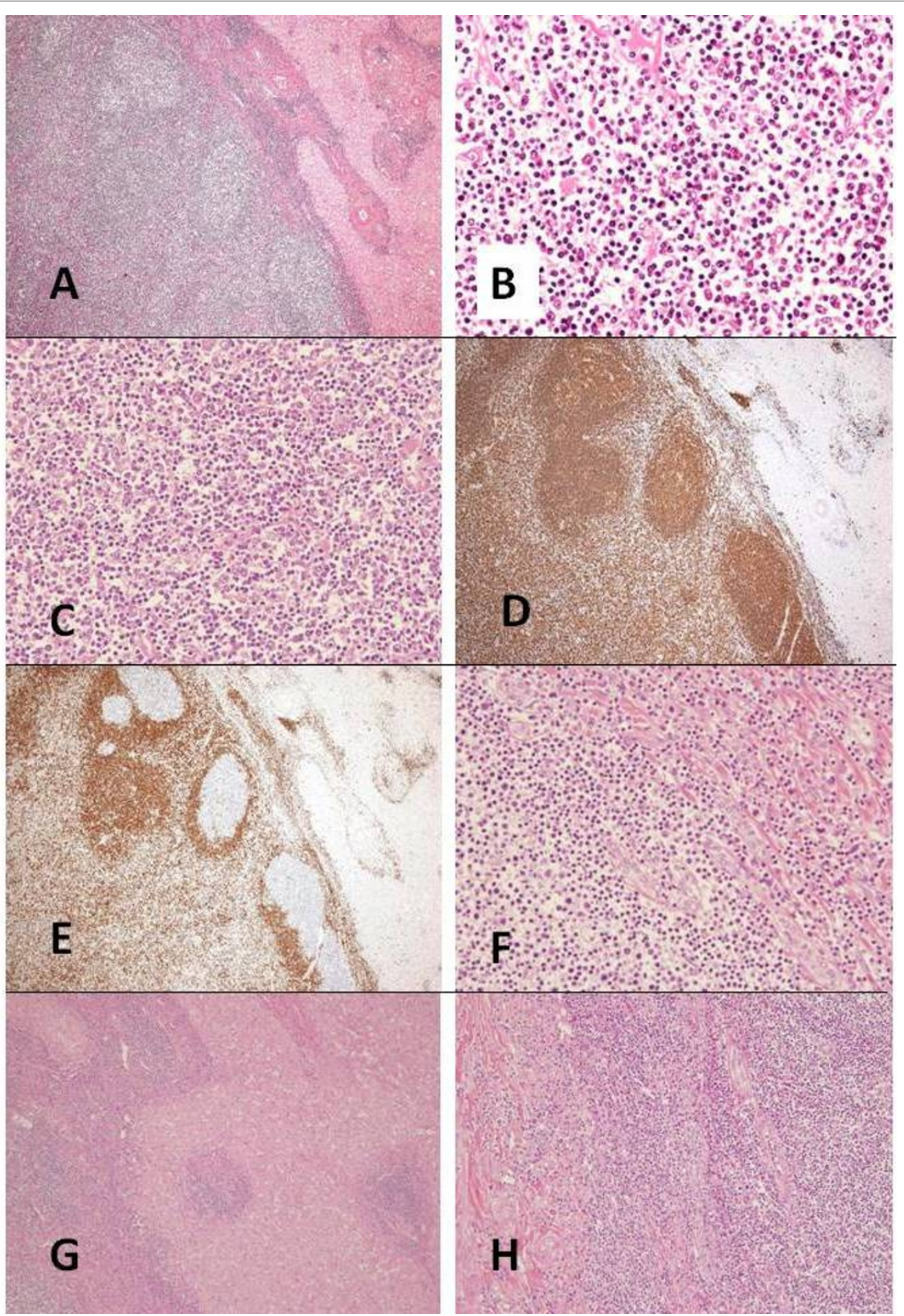

Figure 5 Microscopic appearance of the lesion. (A) Low-power view of the tumor showing dense lymphocytic infiltration with lymph follicles (hematoxylin and eosin, original magnification $\times 4$ ). (B) Interfollicular areas are infiltrated with small to intermediate-sized lymphocytes with pale cytoplasm, which are characteristic features of hepatic pseudolymphoma as well as marginal zone B-cell lymphoma (hematoxylin and eosin, original magnification $\times 40$ ). (C) Intermediate-sized atypical lymphocytes are observed (hematoxylin and eosin, original magnification $\times 40)$. (D) Most of the lymphoid cells are positive for CD20. These cells are negative for CD5, which rules out other small B-cell non Hodgkin lymphomas, including lymphocytic lymphoma and mantle cell lymphoma (original magnification $\times 4$ ). (E) BCl-2 expression in the mantle zones and the interfollicular areas (original magnification $\times 4$ ). (F) Lymphoepithelial lesions are observed at the bile ducts (hematoxylin and eosin, original magnification $\times 40$ ). (G) At the edge of the nodule, lymphocytic infiltration extends into perinodular portal tracts (hematoxylin and eosin, original magnification $\times 10$ ). $(\mathrm{H})$ Bile ducts are observed at the periphery of the nodule (hematoxylin and eosin, original magnification $\times 10$ ). 
non-neoplastic lesion mimicking MALT lymphoma including HPL, reactive lymphoid hyperplasia, or nodular lymphoid lesion, but still insufficient to distinguish these conditions. Polymerase chain reaction was performed to detect monoclonal immunoglobulin heavy chain (IGH) gene rearrangement in an attempt to differentiate these two entities, but was unsuccessful due to degradation of extracted DNA from the specimen, presumably partly because of deleterious effect on DNA integrity by the previous local tumor ablation using transcatheter arterial chemo-embolization. The background liver showed 30\% macrovesicular steatosis with scattered ballooned cells and perivenular fibrosis, suggesting non-alcoholic fatty liver disease (NAFLD) or early non-alcoholic steatohepatitis (NASH). No histological finding suggested concomitant primary biliary cirrhosis (PBC) or viral hepatitis.

The postoperative course of this patient was uneventful and she was discharged from the hospital on postoperative day 8. Any adjuvant chemotherapy or radiotherapy was not indicated, considering that the tumor was confined in the liver with no extrahepatic involvement, and she is currently doing well with no sign of relapse 13 months after the surgery.

\section{Discussion}

Hepatic pseudolymphoma (HPL), also known as reactive lymphoid hyperplasia, or nodular lymphoid lesion, is extremely rare disease entity and so far 35 cases have been reported worldwide [4,6-9] since the first report by Sharifi et al [10]. Its pathogenesis and clinical implications have not been fully elucidated. According to the recently proposed criteria by Zen et al, the present case reported here would be diagnosed with HPL, although not confirmed by molecular examination, such as detection of gene rearrangement.

Primary hepatic marginal zone B-cell lymphoma of the mucosa-associated lymphoid tissue type (MALT lymphoma), also rare entity with only 48 cases being reported in the worldwide literature [11-22] since the first report by Isaacson et al [23], accounts for $1.6-3 \%$ of PHL $[24,25]$, is the most important differential diagnosis from HPL.

The etiopathogenesis of HPL remains unclear, although $27 \%$ of the patients had chronic liver diseases including HBV- or HCV-related liver cirrhosis, and moreover, $23 \%$ had autoimmune disorders, such as PBC, in extrahepatic organs [26]. In terms of background disorders, this figure is comparable with that of MALT lymphoma, where half of the patients have chronic inflammatory liver diseases including autoimmune disorders $[11,21,27,28]$. The similarity would imply the common pathogenesis of these two conditions. In this regard, several authors have proposed that chronic persistent, prolonged immunogenic stimulation targeted either to infectious agents, such as Helicobacter pylori and $\mathrm{HCV}$, and autoimmune diseases, such as PBC, Hashimoto thyroiditis, and Sjögren syndrome, would induce development of acquired MALT and subsequently MALT lymphoma [28], and/or HPL during this process as well [29].

As a background liver condition associating with HPL, in accordance with the case reported by Zen et al [26], our case would suggest the possible role for NAFLD/ $\mathrm{NASH}$ as a pathogenesis in this entity through chronic persistent inflammatory stimulation in the liver, though via non-immunological pathway, yet further study is required on this matter.

Clinical resemblance includes the age of patients (mean age, 55.1 vs. 61.4 years old, HPL vs. MALT lymphoma), and tumor characteristics including the size (size range, $0.5-5.5$ vs. 2-7.7 cm, HPL vs. MALT lymphoma) and the number, where the majority of cases had solitary tumor at presentation in both entities $(81 \%$ vs. $78 \%$, HPL vs. MALT lymphoma). The single pronounced difference would be the female preponderance in HPL ( $86 \%$ vs. $51 \%$, HPL vs. MALT lymphoma, 4 , $16,26)$.

The diagnosis of HPL, not to mention the preoperative one, appears challenging. In fact, the case report by Sato et al indicating the transformation of HPL into lymphoma [30] would implicate the significance, as well as difficulty, of differential diagnosis of these two conditions. In our case, since the lack of molecular diagnosis hampered the definitive diagnosis, there still remains insufficiency in differential diagnosis from hepatic MALT lymphoma [26]. Therefore, molecular analysis should be routinely undertaken as the most potent diagnostic tool in such a controversial case. However, at the same time, it should be noted that even a clonal IGH rearrangement would not be a gold standard for a diagnosis of lymphoma, as suggested by Geyer et al. in the setting of lower female genital tract, and therefore both routine microscopic findings and detailed clinical information remain paramount in establishing the correct diagnosis [31]. In this context, the clinical course of this patient on careful follow-up hereafter might elucidate the essentials of this disorder.

Regarding the diagnostic significance of FDG-PET, no report on HPL is currently available. In contrast, FDGPET has been reported in the recent two reports as a useful and convenient modality for the diagnosis of hepatic MALT lymphoma [21,22]. Considering the positive uptake of FDG seen in our case, however, this examination would not be used solely to differentiate the two conditions.

Natural history of HPL is yet delineated. Malignant transformation of pseudolymphoma into true lymphoma 
has been reported in the various organs, such as lung, stomach, and skin [32-34], but actual frequency have not evaluated, since the majority of cases underwent surgical resection under a suspicion for malignancy. Regarding liver, since only one case report is available [30], the possibility of transformation of HPL into hepatic MALT lymphoma could not be determined. Therefore, surgical removal is the treatment of choice for these conditions [35]. Further accumulation of clinical data is required to clarify this matter.

With respect to treatment strategy, reported cases demonstrated that even MALT lymphoma has a favorable prognosis compared with other subtypes of PHL; the former is usually limited to the liver and surgical resection cures the patient in most cases [36]. Also, when diagnosis is confirmed after needle biopsy, non-resection treatment procedures would be permitted, such as radiofrequency ablation [37] instead of surgical resection. Furthermore, in case of HPL, simple observation proved to be practically enough since spontaneous diminution of tumor size or even regression of tumor has been reported $[26,38]$, yet further accumulation of data is needed.

Regarding prognosis after treatment, since no recurrence of MALT lymphoma has been reported to date to occur after adequate surgical resection or chemotherapy treatments [21], even if the tumor is true neoplastic lesion, as long as it remains low-grade malignancy, the surgical outcome would be comparable with that for HPL. However, it should be noted that there is a single report of local recurrence after surgical resection, suggesting the importance of close post-treatment follow-up [39]. Considering the relatively short duration of observation period in the reported cases, vigilant follow-up of the patients including our case would be required.

PHL and lymphoid lesions in general should be considered in the differential diagnosis of space occupying lesions of the liver in the absence of elevated levels of ordinary tumor markers including AFP and CEA [40]. In addition, it is also important to distinguish HPL and MALT lymphoma from others, particularly from more aggressive type, such as mantle cell lymphoma [41]. However, because of their indolent, localized clinical presentation, diagnosis is often accompanied by substantial difficulty, with the majority of cases being diagnosed incidentally. Admitted that even in case of lymphoma, there is a certain chance of cure by means of medical treatment without surgery, en bloc resection of the hepatic tumor would be recommended as a principle procedure for subsequent diagnosis and decision for treatment. Needle biopsy failed to present a diagnosis in our case, partly because the tumor was among the smallest of the reported cases in the literatures. Finally, in such situation, laparoscopic approach would provide a reasonable procedure of less invasiveness for patients [42].

\section{Conclusion}

HPL and MALT lymphoma are very rare. We herein report a case with a space occupying lesion in the left lateral segment of the liver, which was completely resected by laparoscopic-assisted lateral segmentectomy. The tumor of maximal $1.0 \mathrm{~cm}$ in diameter was consisted of aggregation of lymphocytes of predominantly B-cell, containing multiple lymphocyte follicles positive for $\mathrm{CD} 10$ and bcl-2, consistent with a diagnosis of HPL, but still necessitating differential diagnosis from MALT lymphoma. Since the accurate diagnosis of this entity is difficult, laparoscopic approach would provide a reasonable procedure of diagnostic and therapeutic advantage with minimal invasiveness for patients. Considering that the real nature of this entity remains unclear to date, vigilant follow-up of patient is essential.

\section{Consent}

Written informed consent was obtained from the patient for publication of this case report and any accompanying images. A copy of the written consent is available for review by the Editor-in-Chief of this journal.

\section{List of abbreviations}

HPL: hepatic pseudolymphoma; MALT: mucosa-associated lymphoid tissue; $\mathrm{PHL}$ : primary hepatic lymphoma; LDH: lactate dehydrogenase; s-IL2: soluble interleukin 2; CEA: carcinoembryonic antigen; AFP: alpha-fetoprotein; HCV: hepatitis $C$ virus; $C T$ : computed tomography; MRI: magnetic resonance imaging; HCC: hepatocellular carcinoma; Gd-EOB-DTPA: gadolinium ethoxybenzyl diethylenetriamine pentaacetic acid; FDG-PET:

fluorodeoxyglucose-positron emission tomography; SUV: standardized uptake value; IGH: immunoglobulin heavy chain; NAFLD: non-alcoholic fatty liver disease; NASH: non-alcoholic steatohepatitis; PBC: primary biliary cirrhosis.

\section{Author details}

${ }^{1}$ Department of General and Gastroenterological Surgery, Osaka Medical College Hospital, 2-7 Daigaku-machi, Takatsuki, Osaka 569-8686, Japan. 2Division of Comprehensive Medicine, Department of Clinical and Laboratory, Osaka Medical College Hospital, 2-7 Daigaku-machi, Takatsuki, Osaka 569-8686, Japan. ${ }^{3}$ Department of Internal Medicine, Osaka Medical College Hospital, 2-7 Daigaku-machi, Takatsuki, Osaka 569-8686, Japan. ${ }^{4}$ Department of Pathology, Osaka Medical College Hospital, 2-7 Daigakumachi, Takatsuki, Osaka 569-8686, Japan. ${ }^{5}$ Department of Radiology, Osaka Medical College Hospital, 2-7 Daigaku-machi, Takatsuki, Osaka 569-8686, Japan. ${ }^{6}$ Department of Surgical Pathology, Hokkaido University Hospital, North 15, West 7, Kita-ku, Sapporo 060-8638, Japan.

\section{Authors' contributions}

$\mathrm{MH}$ conceived the study concept and design, was involved with patient care and drafted the manuscript and literature review. NY, FH, MA, KM, AT, $\mathrm{KY} \mathrm{HH}$, and $\Pi$ were involved with formation of the study concept and design, patient care and drafting of the manuscript and literature review. NT carried out the operation on the patient and was the main contributor in the writing of the manuscript. All authors have read and approved the final version of the manuscript.

\section{Competing interests}

The authors declare that they have no competing interests.

Received: 3 May 2010 Accepted: 13 January 2011

Published: 13 January 2011 


\section{References}

1. Caccamo D, Pervez NK, Marchevsky A: Primary lymphoma of the liver in the acquired immunodeficiency syndrome. Arch Pathol Lab Med 1986, 110:553-555.

2. Freeman C, Berg JW, Cutler SJ: Occurrence and prognosis of extranodal lymphomas. Cancer 1972, 29:252-260

3. Ishida M, Nakahara T, Mochizuki Y, Tsujikawa T, Andoh A, Saito Y, Yamamoto H, Kojima F, Hotta M, Tani T, Fujiyama Y, Okabe H: Hepatic reactive lymphoid hyperplasia in a patient with primary biliary cirrhosis. World J Hepatol 2010, 2:387-391.

4. Okada T, Mibayashi H, Hasatani K, Hayashi $Y$, Tsuji S, Kaneko $Y$, Yoshimitsu M, Tani T, Zen Y, Yamagishi M: Pseudolymphoma of the liver associated with primary biliary cirrhosis: a case report and review of literature. World J Gastroenterol 2009, 15:4587-4592.

5. Matsumoto K, Yoshimoto J, Sugo H, Kojima K, Futagawa S, Matsumoto T: Relationship between the histological degrees of hepatitis and the postoperative recurrence of hepatocellular carcinoma in patients with hepatitis C. Hepatol Res 2002, 23:196-201.

6. Sato K, Ueda Y, Yokoi M, Hayashi K, Kosaka T, Katsuda S: Reactive lymphoid hyperplasia of the liver in a patient with multiple carcinomas: a case report and brief review. J Clin Pathol 2006, 59:990-992.

7. Takahashi H, Sawai H, Matsuo Y, Funahashi H, Satoh M, Okada Y, Inagaki H, Takeyama H, Manabe T: Reactive lymphoid hyperplasia of the liver in a patient with colon cancer: report of two cases. BMC Gastroenterol 2006, 6:25.

8. Park HS, Jang KY, Kim YK, Cho BH, Moon WS: Histiocyte-rich reactive lymphoid hyperplasia of the liver: unusual morphologic features. $J$ Korean Med Sci 2008, 23:156-160.

9. Machida T, Takahashi T, Itoh T, Hirayama M, Morita T, Horita S: Reactive lymphoid hyperplasia of the liver: a case report and review of literature. World J Gastroenterol 2007, 13:5403-5407.

10. Sharifi S, Murphy M, Loda M, Pinkus GS, Khettry U: Nodular lymphoid lesion of the liver: an immune-mediated disorder mimicking low-grade malignant lymphoma. Am J Surg Pathol 1999, 23:302-308.

11. Nakayama S, Yokote T, Kobayashi K, Hirata Y, Akioka T, Miyoshi T, Oka S, Hiraoka N, Iwaki K, Takayama A, Fukui H, Tsuda Y, Takubo T, Tsuii M, Higuchi K, Hanafusa T: Primary hepatic MALT lymphoma associated with primary biliary cirrhosis. Leuk Res 2010, 34:17-20.

12. Prabhu RM, Medeiros LJ, Kumar D, Drachenberg Cl, Papadimitriou JC, Appelman HD, Johnson LB, Laurin J, Heyman M, Abruzzo LV: Primary hepatic low-grade B-cell lymphoma of mucosa-associated lymphoid tissue (MALT) associated with primary biliary cirrhosis. Mod Pathol 1998, 11:404-410.

13. Maes M, Depardieu C, Dargent $J$, Hermans M, Verhaeghe $J L$, Delabie J, Pittaluga S, Troufléau P, Verhest A, De Wolf-Peeters C: Primary low-grade Bcell lymphoma of MALT-type occurring in the liver: a study of two cases. J Hepatol 1997, 27:922-927.

14. Chen F, Ike O, Wada H, Hitomi S: Pulmonary mucosa-associated lymphoid tissue lymphoma 8 years after resection of the same type of lymphoma of the liver. Jpn J Thorac Cardiovasc Surg 2000, 48:233-235.

15. Mizuno S, Isaji S, Tabata M, Uemoto S, Imai H, Shiraki K: Hepatic mucosaassociated lymphoid tissue (MALT) lymphoma associated with hepatitis C. J Hepatol 2002, 37:872-873.

16. Murakami J, Fukushima N, Ueno H, Saito T, Watanabe T, Tanosaki R, Kobayashi $Y$, Matsuno $Y$, Tobinai K: Primary hepatic low-grade B-cell lymphoma of the mucosa-associated lymphoid tissue type: a case report and review of the literature. Int J Hematol 2002, 75:85-90.

17. Bronowicki JP, Bineau C, Feugier $P$, Hermine O, Brousse N, Oberti F, Rousselet MC, Dharancy S, Gaulard P, Flejou JF, Cazals-Hatem D, Labouyrie E: Primary lymphoma of the liver: clinical-pathological features and relationship with HCV infection in French patients. Hepatology 2003, 37:781-787.

18. Takeshima F, Kunisaki M, Aritomi T, Osabe M, Akama F, Nakasone T, Niino D, Katayama S, Isomoto H, Omagari K, Mizuta Y, Murata I, Kohno S: Hepatic mucosa-associated lymphoid tissue lymphoma and hepatocellular carcinoma in a patient with hepatitis B virus infection. J Clin Gastroenterol 2004, 38:823-826.

19. Orrego M, Guo L, Reeder C, De Petris G, Balan V, Douglas DD, Byrne T, Harrison E, Mulligan D, Rodriguez-Luna H, Moss A, Reddy K, Rakela J, Vargas HE: Hepatic B-cell non-Hodgkin's lymphoma of MALT type in the liver explant of a patient with chronic hepatitis C infection. Liver Transp/ 2005, 11:796-799.

20. Mahjoub KW, Chaumette-Planckaert MT, Murga Penas EM, Dierlamm J, Leroy K, Delfau MH, Loriau J, Gaulard P, Delchier JC, Zafrani ES, CopieBergman C: Primary hepatic lymphoma of mucosa-associated lymphoid tissue type: a case report with cytogenetic study. Int J Surg Pathol 2008, 16:301-307.

21. Doi H, Horiike N, Hiraoka A, Koizumi Y, Yamamoto Y, Hasebe A, Ichikawa S, Yano M, Miyamoto $Y$, Ninomiya T, Ishimaru $Y$, Miyagawa M, Takamura K, Kawasaki H, Kozuka T, Maeda T, Yoshino T: Primary hepatic marginal zone B cell lymphoma of mucosa-associated lymphoid tissue type: case report and review of the literature. Int J Hematol 2008, 88:418-423.

22. Cabassa P, Morone M, Matricardi L: An unusual liver mass. Gastroenterology 2010, 138:e7-9.

23. Isaacson PG, Banks PM, Best PV, McLure SP, Muller-Hermelink HK, Wyatt الر Primary low-grade hepatic B-cell lymphoma of mucosa-associated lymphoid tissue (MALT)-type. Am J Surg Pathol 1995, 19:571-575.

24. Dargent $J \mathrm{~L}$, De Wolf-Peeters $C$ : Liver involvement by lymphoma: identification of a distinctive pattern of infiltration related to T-cell/ histiocyte-rich B-cell lymphoma. Ann Diagn Pathol 1998, 2:363-269.

25. Lei Kl: Primary non-Hodgkin's lymphoma of the liver. Leuk Lymphoma 1998, 29:293-299.

26. Zen Y, Fujii T, Nakanuma Y: Hepatic pseudolymphoma: a clinicopathological study of five cases and review of the literature. Mod Pathol 2010, 23:244-250

27. Ascoli V, Lo Coco F, Artini M, Levrero M, Martelli M, Negro F: Extranodal lymphomas associated with hepatitis $\mathrm{C}$ virus infection. Am J Clin Pathol 1998, 109:600-609.

28. Ye MQ, Suriawinata A, Black C, Min AD, Strauchen J, Thung SN: Primary hepatic marginal zone B-cell lymphoma of mucosa-associated lymphoid tissue type in a patient with primary biliary cirrhosis. Arch Pathol Lab Med 2000, 124:604-608

29. Okubo H, Maekawa H, Ogawa K, Wada R, Sekigawa I, lida N, Maekawa T, Hashimoto H, Sato N: Pseudolymphoma of the liver associated with Sjögren's syndrome. Scand J Rheumatol 2001, 30:117-119.

30. Sato S, Masuda T, Oikawa H, Satoh T, Suzuki Y, Takikawa Y, Yamazaki K, Suzuki K, Sato S: Primary hepatic lymphoma associated with primary biliary cirrhosis. Am J Gastroenterol 1999, 94:1669-1673.

31. Geyer JT, Ferry JA, Harris NL, Young RH, Longtine JA, Zukerberg LR: Florid reactive lymphoid hyperplasia of the lower female genital tract (lymphoma-like lesion): a benign condition that frequently harbors Clonal immunoglobulin heavy chain gene rearrangements. Am J Surg Pathol 2010, 34:161-168.

32. Koss MN, Hochholzer L, Nichols PW, Wehunt WD, Lazarus AA: Primary nonHodgkin's lymphoma and pseudolymphoma of lung: a study of 161 patients. Hum Pathol 1983, 14:1024-1038.

33. Brooks JJ, Enterline HT: Gastric pseudolymphoma. Its three subtypes and relation to lymphoma. Cancer 1983, 51:476-486.

34. Kulow BF, Cualing H, Steele P, VanHorn J, Breneman JC, Mutasim DF, Breneman DL: Progression of cutaneous B-cell pseudolymphoma to cutaneous B-cell lymphoma. J Cutan Med Surg 2002, 6:519-528.

35. Maehara N, Chijiiwa K, Makino I, Ohuchida J, Kai M, Kondo K, Moriguchi S, Marutsuka K, Asada Y: Segmentectomy for reactive lymphoid hyperplasia of the liver: Report of a case. Surg Today 2006, 36:1019-1023.

36. Chatelain D, Maes C, Yzet T, Brevet M, Bounicaud D, Plachot JP, Verhaeghe P: [Primary hepatic lymphoma of MALT-type: a tumor that can simulate a liver metastasis]. Ann Chir 2006, 131:121-124, [Article in French].

37. Hamada M, Tanaka Y, Kobayashi Y, Takeshita E, Joko K: A case of MALT lymphoma of the liver treated by RFA and Rituximab. Nippon Shokakibyo Gakkai Zasshi 2006, 103:655-660, [Article in Japanese].

38. Ota H, Isoda N, Sunada F, Kita H, Higashisawa T, Ono K, Sato S, Ido K, Sugano K: A case of hepatic pseudolymphoma observed without surgical intervention. Hepatol Res 2006, 35:296-301.

39. Gockel HR, Heidemann J, Lugering A, Mesters RM, Parwaresch R, Domschke $W$, Lugering $\mathrm{N}$ : Stable remission after administration of rituximab in a patient with primary hepatic marginal zone B-cell lymphoma. Eur J Haematol 2005, 74:445-447.

40. Masood A, Kairouz S, Hudhud KH, Hegazi AZ, Banu A, Gupta NC: Primary non-Hodgkin lymphoma of liver. Curr Oncol 2009, 16:74-77. 
41. Kirk CM, Lewin D, Lazarchick J: Primary hepatic B-cell lymphoma of mucosa-associated lymphoid tissue. Arch Pathol Lab Med 1999, 123:716-719.

42. Tokunaga Y, Sasaki H, Matsueda S, Kawasahi T, Saito T: Clinical role of laparoscopic hepatectomy using vessel sealer and soft coagulation for small hepatic tumors suspected of malignancy. Hepatogastroenterology 2009, 56:1714-1718.

doi:10.1186/1477-7819-9-3

Cite this article as: Hayashi et al: An operative case of hepatic pseudolymphoma difficult to differentiate from primary hepatic marginal zone B-cell lymphoma of mucosa-associated lymphoid tissue. World Journal of Surgical Oncology 2011 9:3.

Submit your next manuscript to BioMed Central and take full advantage of:

- Convenient online submission

- Thorough peer review

- No space constraints or color figure charges

- Immediate publication on acceptance

- Inclusion in PubMed, CAS, Scopus and Google Scholar

- Research which is freely available for redistribution

Submit your manuscript at www.biomedcentral.com/submit
() Biomed Central 